\title{
Gastrointestinal Parasitism in Goats and Role of Seasonal Changes on Their Prevalence: A Study of Nepal
}

\author{
Rajes Kumar Das ${ }^{1}$, Prabin Neupane ${ }^{2}$ and Endang Sulistyowati ${ }^{3}$ \\ ${ }^{1}$ Faculty of Public Health, Universitas Indonesia, Indonesia \\ 2Department of Microbiology, Kathmandu College of Science and Technology, Nepal \\ ${ }^{3}$ Department of Animal Science, Faculty of agriculture, University of Bengkulu, Indonesia \\ Email address: dasrajesh5131@gmail.com
}

\begin{abstract}
Goat farming is the good source of income for people living in countryside, Nepal. This occupation supports socioeconomic living of many people in developing countries. Gastro-parasitic infections in goats can decrease the meat supply in a country where demand of goat meat is ever increasing. The objective of this study was to identify the gastrointestinal parasites in feces of goats and impact of seasonal changes on their prevalence. This is a cross-sectional study done on 212 goats from Kapilbastu, Nepal. For this study, feces of goats were collected during summer and winter and observed microscopically to find the causative organisms. The result showed the helminths from trematode $(22.22 \%)$, cestode $(12.5 \%)$ and nematode $(65.27 \%)$ caused heavy gastrointestinal infection in 144 microscopically positive samples taken from Kapilbastu, Nepal. The major helminths were Toxocara (16.66\%), Oesophagnum (8.32\%), Strongyloides (6.25\%) and Trichuris $(4.86 \%)$ among nematodes, Fasciola (15.97\%) caused highest infection among trematode and Taenia $(9.72 \%)$ among cestode. The prevalence of these infections was significantly higher during summer than winter. The higher prevalence of these helminths is the indication of supply contaminated food and water. Moreover, unawareness and ignorance about such diseases can increase the infection rate. Proper management of goat farm together with good cattle rearing training can increase the productivity.
\end{abstract}

Key words: Gastrointestinal parasites, Kapilbastu, prevalence, productivity, Socioeconomic

Citation to this paper should be made as follows :

Das, R. K., P. Neupane and E. Sulistyowati. 2019. Gastrointestinal parasitism in goats and role of seasonal changes on their prevalence: A study of Nepal. Agritropica: Journal of Agricultural Science. 2 (1): 33-39.

DOI: https://doi.org/10.31186/J.Agritropica.2.1.33-39

\section{INTRODUCTION}

Goat production is an important occupation that supports socioeconomic life throughout the developing countries. Goat farming in Nepal is increasing every year due to increasing demand of meat and is considered potential small scale industry due to low capital investment and higher profit. Usually, many Nepalese farmer living in countryside rear goats as a supplementary occupation and this solve their monetary problem to certain extent (Ghimire 1987).

Although goats are resistant to many diseases, gastrointestinal parasitic infections (GPI) can occur mainly due to subtropical climate and poor management. Poor management and unsanitary habitats can lead to several infections which ultimately reduces meat production from goats. GPI affect millions of livestock worldwide causing heavy economic loss. Furthermore, many studies show seasonal changes can affect the growth rate and prevalence rate GPI in goats (Nwosu et al., 2007, Sukupayo and Rayamajhi 2018). Besides seasonal changes, global warming and increasing environmental pollution have aided the spread of parasitic diseases. 
Among parasitic diseases, helminths are the commonly occurring parasites that affect survival and productivity of these animals. Gastrointestinal (GI) nematodes rank highest on global index with Haemonchus contortus on top (Perry et al., 2002). Animals are exposed to massive helminths infection when they are maintained in an unhygienic, dark, congested and poorly kept ranches and also when fed with contaminated food and water. The goats suffering from GPI show reduced feed intake and alteration of gastrointestinal motility leading to diarrhea. This has negative impact on host metabolism causing the reduced protein and energy retention, and disturbed mineral and water balance (Blackburn et al 1991). The most common intestinal helminths causing GPI in goats are Trichostrongylus spp, Heamonchus spp, Oesophagostumum spp, Fasciola spp, Bunostomum spp, Trichuris spp, etc. The larva of intestinal helminth is released after the host ingests the eggs. The larva penetrates the interior part of small intestine for about 2-10 days before moving to the caecum where it moults to adult (Hunter HJB 1994).

Therefore, the present study aimed to identify the prevalence and risk factors associated with GPI in goats in Kapilbastu, Nepal. Knowing the prevalence and risk factors can help to make appropriate control program. This can also serve as reference to other farms and villages and suggest them goat management and elimination of parasitic infections.

\section{RESEARCH METHODS}

\section{Study Area}

The study took place in Kapilbastu which is one of the districts in province No. 5, Nepal. The district is situated at a height of 93 to 1,491 meters (305 to $4,892 \mathrm{ft}$ ) above sea level. It is situated at the Southern plains of Nepal at about 330 $\mathrm{km}$ west from capital city Kathmandu. The district covers a total of $1,738 \mathrm{~km}^{2}$ area. The summer is hot with temperature above $27^{\circ} \mathrm{C}$ and winter temperature remains below $15^{\circ} \mathrm{C}$. Due to extremely hot and cold climatic conditions, the animals suffer from different helminthic diseases.

Animal husbandry is the common occupation of the people living in the countryside of Nepal. They often raise animals like buffalo, cow, goats, sheep etc to support their living. Chicken and goat are the most common source of meat in Nepal. The demand of goat meat is often higher in most of the cities in Nepal which makes the price expensive.

\section{Sample Collection and Storage}

For this study, secondary data source was taken from a study done on goats by Tripathi RP at Tribhuvan University, Nepal in 2015. Fecal samples from goat were collected during summer and winter seasons. Total 212 samples were processed; 106 during summer and 106 during winter. Fresh rectal fecal samples of goats were collected in a labeled plastic bag and were fixed with potassium dichromate $(2.5 \%)$ and then stored in refrigerator at $4^{0} \mathrm{C}$ for later examination by microscopy.

\section{Laboratory Examination}

The fecal goat samples were examined by differential floatation and sedimentation technique. The floatation technique was used for the detection of nematode and cestode eggs. Sedimentation technique is used for the detection of trematode eggs (Chaudhari et al., 2003 and Gibbons et al., 2007). In sedimentation technique, the eggs get deposited at the bottom of the tube after 
the centrifugation with zinc sulphate solution. A drop of deposited material was taken on the slide by pipette and a drop of methylene blue was added. The smear was examined under a microscope at $4 \mathrm{X}$ and $10 \mathrm{X}$.

\section{Statistical Analysis}

Data were analyzed by using chisquare $\left(\mathrm{x}^{2}\right)$ test. A p-value of $<0.05$ was considered significant.

\section{RESULTS AND DISCUSSION}

Out of a total of 212 fecal samples processed through flotation and sedimentation technique, 144 (67.92\%) samples showed the presence of helminthic eggs. This study showed the presence of various helminths from the classes trematode, cestode and nematode. Altogether 18 genera of helminths were observed i.e. 3 genera of trematodes, 2 genera of cestodes and 13 genera of nematodes. The overall prevalence percentage of each species is given in the following table 1 .
Table 1. Helminthic parasites found in

\begin{tabular}{lll}
\multicolumn{2}{c}{ goat fecal sample } & \\
\hline Class & Genera of & Percentage \\
& Helminth & \\
\hline Trematoda & Fasciola & $15.97 \%$ \\
& Dicrocoelium & $3.47 \%$ \\
& Paramphistomum & $2.77 \%$ \\
Cestoda & Taenia sp & $9.72 \%$ \\
& Moniezia & $2.77 \%$ \\
Nematoda & Toxocara & $16.66 \%$ \\
& Oesophagostomum & $8.32 \%$ \\
& Strongyloides & $6.25 \%$ \\
& Trichuris & $4.86 \%$ \\
& Capillaria & $4.86 \%$ \\
& Trichostrongyloid & $3.47 \%$ \\
& Others & $20.85 \%$ \\
\hline
\end{tabular}

\section{Seasonal Prevalence of Helminth Parasites in Goats}

Helminthic infection were higher $86(81.13 \%)$ in summer than winter 57 $(39.6 \%)$ out of 106 samples studied in each seasons. Nematodes caused more infection than other classes. However, the seasonal prevalence of different genera during winter and summer were not found statistically insignificant $(\chi 2=3.749$, $p=0.065$, not shown).

Table2. Seasonal prevalence of helminthic parasites in goat

\begin{tabular}{lllll}
\hline Season & Positive & Trematodes & Cestodes & Nemotodes \\
\hline Summer & $87(60.42 \%)$ & $19(13.19 \%)$ & $12(8.33 \%)$ & $56(38.88 \%)$ \\
Winter & $57(39.6 \%)$ & $13(9.02 \%)$ & $6(4.17 \%)$ & $38(26.39 \%)$ \\
Total & $144(100 \%)$ & $32(22.22 \%)$ & $18(12.5 \%)$ & $94(65.27 \%)$ \\
\hline
\end{tabular}

Seasonal Prevalence of Trematode in Goat

Among trematode class, Fasciola, Dicrocoelium and Paramphistomum were identified from goat feces. These organisms caused infection at higher rate in summer. Fasciola sp infection is the main agent of infection both during summer and winter. Other genera of trematode caused fewer infections (shown in Figure 1). 


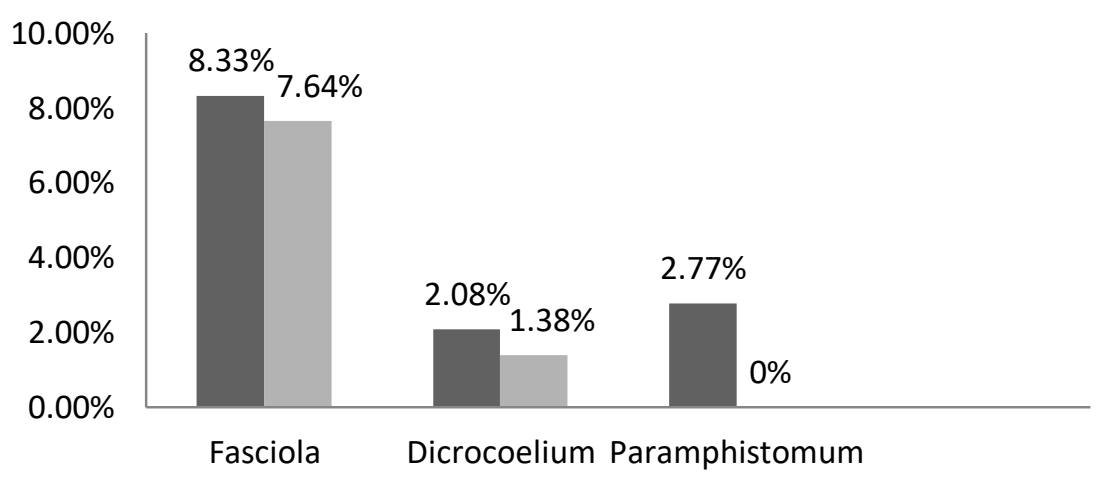

Figure 1. Seasonal prevalence of Trematode in goat

Seasonal prevalence of Cestode in goat

Taenia and Moniezia were the causative agents from class cestode. Taenia infection was higher during summer (5.55\%) than winter (4.16\%). Moniezia infection was also higher in summer but not a big difference than winter.

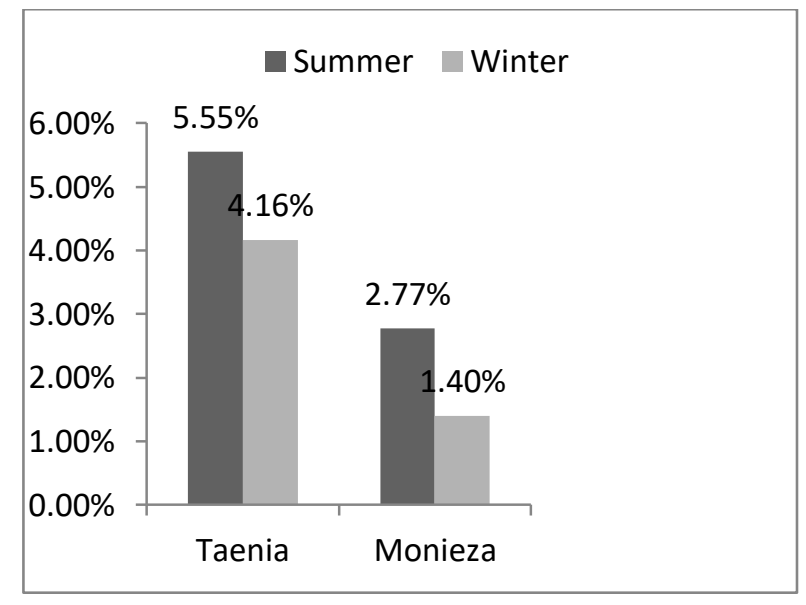

Figure 2. Seasonal prevalence of Cestodes in goat

Seasonal prevalence of Nematode in goat Nematodes were the main causative agent of parasitic infection in goats among all classes. Toxocara dominated the infection (8.33\%) among all other genera both in summer and winter. Oesophagostomum was second major infection causing genera with prevalence rate of $4.16 \%$ both in summer and winter. Strongyloides, Trichuris, Capillaria and others also caused significant number of infections.

Table3. Seasonal prevalence of Nematodes

\begin{tabular}{llll}
\hline Nematode & \multicolumn{1}{c}{ Summer } & \multicolumn{1}{c}{ Winter } & \multicolumn{1}{c}{ Total } \\
\hline Toxocara & $12(8.33 \%)$ & $12(8.33 \%)$ & $24(16.66 \%)$ \\
Chabertia & $4(2.77 \%)$ & $2(1.38 \%)$ & $6(4.16 \%)$ \\
Capillaria & $4(2.77 \%)$ & $3(2.08 \%)$ & $7(4.86 \%)$ \\
Oesophagostomum $6(4.16 \%)$ & $6(4.16 \%)$ & $12(8.32 \%)$ \\
Haemonchus & $2(1.38 \%)$ & $3(2.08 \%)$ & $5(3.47 \%)$ \\
Cooperia & $2(1.38 \%)$ & $1(0.7 \%)$ & $3(2.08 \%)$ \\
Strongyloides & $5(3.47 \%)$ & $4(2.77 \%)$ & $9(6.25 \%)$ \\
Trichuris & $4(2.77 \%)$ & $3(2.08 \%)$ & $7(4.86 \%)$ \\
Trichostrongyloid & $4(2.77 \%)$ & $1(0.7 \%)$ & $5(3.47 \%)$ \\
Bunostomium & $4(2.77 \%)$ & $0(0 \%)$ & $4(2.77 \%)$ \\
Others & $9(6.25 \%)$ & $3(2.08 \%)$ & $12(8.33 \%)$
\end{tabular}

Goats are the popular source of animal meat and also have great economic value for the people from developing countries like Nepal. The economic value of goats is due to their ability to convert plant products and household residues into meat, skins and milk. Due to their grazing habits and physiological characteristics, they are able to browse on plants that can lead to a more efficient use of the natural resource base and add 
flexibility to the management of livestock. Although goats are hardy and welladapted to harsh climates, gastrointestinal (GI) parasitic infections are more often inevitable. GI parasitic infections in goats cause considerable economic losses as a consequence of mortality in infected animals and reduced weight gain. Most common GI parasites in goats are helminths and coccidia (Warairu et al., 1993).

The overall prevalence of GI parasitic infections in goats was $67.92 \%$. This result is in accordance with a study in Jammu Province, India ( Khajuria et al., 2012). This is also nearly the same with study by Karki et al. (2011) in Nepal. Higher infections were recorded during summer season $(60.42 \%)$ than winter season 57 (39.6\%). Classes of helminths i.e. trematode, cestode and nematode were identified in the fecal samples. Most of the infections were caused by nematodes and majority of them are Toxocara (16.66\%), Oesophagostomum (8.32\%), Strongyloides $(6.25 \%)$ and others. Among trematode, Fasciola caused highest number of infections (15.97\%). Likewise, Taenia (9.72\%) was major agent among cestoda. Such infections in goat ultimately lead to poor growth rate, reduced weight, diarrhea and anemia and thus cause economic loss. Infections commonly arise due to poor hygienic conditions or fodder and higher chance of during weaning period.

Examinations of fecal samples revealed the prevalence of GI parasitic infections in goats throughout the year. During this study, there were considerable differences for the development and propagation of parasites depending on seasons. Moreover, summer season favors the spread GI parasites than winter $(60.42 \%>39.6 \%)$. Nematodes caused highest number of infections among all parasites; $38.88 \%$ in summer and $26.39 \%$ winter. Cestodes caused minimum number infections; $8.33 \%$ in summer and $4.17 \%$ in winter. All the classes of helminths identified during fecal examination showed higher prevalence during summer. In a study by Sukupayo and Rayamajhee (2018), nematodes were the highest occurring helminths followed by trematode and cestode and prevalence of GPI was also in accordance with our study. Factors responsible for this may be constant exposure to infections, rapid growth of infecting organisms and continuous deposit of infections on the pastures by adult animals as well as poor animal husbandry practices.

The prevalence rate of trematode seems higher for Fasciola, $8.33 \%$ in summer and $7.14 \%$ in winter. This prevalence rate is not a big difference depending on seasons. Also, Dicrocoelium prevalence was found but very few, 2.08\% in summer and $1.38 \%$ in winter. Similarly, the present also found there was significant number cestode infection in goats. Paramphistomum was also noticed during the fecal examination but only during summer (2.775). Likewise, cestode consisted of genera Taenia and Moniezia. Among them, Taenia was the mojor threat with prevalence rate $5.55 \%$ rate in summer and $4.16 \%$ in winter. Besides, Moniezia sp also posed little prevalence in goats. The prevalence rate was $2.77 \%$ in summer and $1.40 \%$ in winter. Furthermore, various genera of nematode were identified in prevalence. Among the major threats were Toxocara with prevalence rate $8.33 \%$ both in summer and winter. Oesophagostomum also caused considerable number infections; $4.16 \%$ both in summer and winter. Other main agents are Strongyloides, Trichuris and others. The prevalence caused by parasites like Toxocara, Oesophagnum and some others 
were almost the same both in summer and winter. The prevalence of nematodes was higher than our study in Meghalaya, India (Das et al 2017) Karki et al (2011) had closer results to our study.

\section{CONCLUSION}

In this study, helminths like trematode, cestode and nematode had major contribution gastro-parasitic infection in goats. Nematodes caused highest prevalence rate. Toxocara, Oesophagostomum, Trichuris etc from nematode, Fasciola from trematode and Taenia from cestode class had higher contribution. Except, Toxocara and Oesophagostomum, all other parasites caused more infection during summer than winter. This higher Infections prevalence rate may due to poor hygienic conditions or contaminated water and fodder. Thus, those farmer rearing cattle like goats should get training on cattle rearing and management of their farm which can help to increase the productivity.

\section{REFERENCES}

Blackburn, H. D., J. L. Rocha, E. P. Figueiredo, M. E. Berne, L. S. Vieira, A. R. Cavalcante, and J. S. Rosa. 1991. Interaction of parasitism and nutrition and their effects on production and clinical parameters in goats. Vet. Parasitol. 40(1): 99-112.

Chaudhri, S.S., S.K. Gupta, D. P. Banerjee, P. K. Bhatnagar and N. S. Ruprah. 2003. General Helminthology. Mannual of Veterinary Helminthology 1:10-184. International Book distributing Company. Lucknow, India.
Das, M., R. Laha, A. Goswami and A. Sen. 2017. Gastrointestinal parasitism of goats in hilly region of Meghalaya, India: Veterinary World, Volume 10, EISSN: 2231-0916

Ghimire, N. P. 1987. Incidence of common diseases of cattle and buffaloes in Surkhet district. Bulletin of Veterinary Science and Animal Husbandry, Nepal, 15:95-101.

Gibbons, L. M., D. E. Jacobs, M.T. Fox, and J. Hansen. 2007. Faecal Examination for Helminth parasites. The RVC/FAO Guide to Veterinary Diagnostic Parasitology, Electronic Media at the Royal Veterinary College London.

Hunter, H. J. B. 1994. Animal Health. Volume 2: Specific Diseases. MacMillan Press, London.

Karki, K., B. K. Bashir, and J.R. Subedi. 2011. A case study on seasonal prevalence of Helminth parasites in goats (capra hircus) in Kalanki (Khasibazar), Kathmandu, Nepal Res J Anim Sci 5(2): 25-26

Khajuria, J.K., R. Katoch A. Yadav. 2013. Seasonal prevalence of gastrointestinal helminths in sheep and goats of middle agro-climatic zone of Jammu province. Indian Society for zarasitology. J Parasit Dis. 37(1):21-25.

Nwosu, C. O., P.P. Madu, and W.S. Richards. 2007. Preva-lence and seasonal changes in the population of gastroin-testinal nematodes of small ruminants in the semi-arid zone of north-eastern Nigeria. Veterinary Parasitolo-gy.144(1-2):118124. 
Perry, B. D., R. F. MC Randolph, J.J. Dermott, K. R. Sones, P. K. Thornton. 2002. Investing in animal health research to alleviate poverty. Research proceedings. International Livestock Research Institute (ILRI), Nairobi, p 148.

Sukupayo, P., B. Rayamajhee. 2018. Prevalence of intestinal helminth parasites in goats of Koshi rural munucipality-11, Nepal IJSER. 9 (7), July-2018.

Waruiru, R.M., P. G. Mbuthia, and C. O. Kimoro. 1993. Prevalence of gastrointestinal parasites and liverflukes in calves in Mathira division of Nyeri District, Kenya. Bull. Anim. Health Prod. Afr., 41: 291-296 